\title{
Summary of Vulcan Calculations
}

J. D. Colvin

U.S. Department of Energy

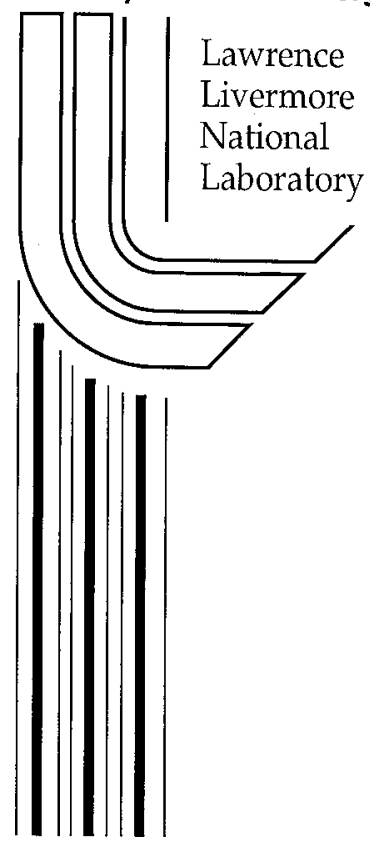

March 23, 2000

Livermore

National

Laboratory 



\section{DISCLAIMER}

This document was prepared as an account of work sponsored by an agency of the United States Government. Neither the United States Government nor the University of California nor any of their employees, makes any warranty, express or implied, or assumes any legal liability or responsibility for the accuracy, completeness, or usefulness of any information, apparatus, product, or process disclosed, or represents that its use would not infringe privately owned rights. Reference herein to any specific commercial product, process, or service by trade name, trademark, manufacturer, or otherwise, does not necessarily constitute or imply its endorsement, recommendation, or favoring by the United States Government or the University of California. The views and opinions of authors expressed herein do not necessarily state or reflect those of the United States Government or the University of California, and shall not be used for advertising or product endorsement purposes.

Work performed under the auspices of the U. S. Department of Energy by the University of California Lawrence Livermore National Laboratory under Contract W-7405-Eng-48.

This report has been reproduced directly from the best available copy.

Available to DOE and DOE contractors from the Office of Scientific and Technical Information

P.O. Box 62, Oak Ridge, TN 37831

Prices available from (423) 576-8401 http://apollo.osti.gov/bridge/

Available to the public from the National Technical Information Service

U.S. Department of Commerce 5285 Port Royal Rd., Springfield, VA 22161 http://www.ntis.gov/

OR

Lawrence Livermore National Laboratory

Technical Information Department's Digital Library

http://www.llnl.gov/tid/Library.html 

Elisabeth Wolfrum

Institut fuer Plasmaphysik

Max-Planck-Gesellschaft

Boltzmannstr.2

D-85748 Garching bei Muenchen

Dear Elisabeth:

Here is a summary of the results of my calculations compared to your data on the Vulcan imprint experiments.

The material strength makes essentially no difference to the growth of perturbations seeded by the laser imprint. For the low-intensity case (30 J laser energy, beam intensity of $0.5 \times 10^{12} \mathrm{~W} / \mathrm{cm}^{2}$ ) the thin (2 microns) Al foil melts quickly from the front (driven) surface and decompresses quickly from the back surface, so there is actually only a fraction of the foil that is solid and compressed, and then for only a short time. And this solid fraction is not accelerating much during this short time. In particular, the shock (which is at about 250 kbar when it is about half way through the foil) travels entirely through the foil in about $0.25 \mathrm{~ns}$. At 0.3 ns the ablation front is $0.6 \mu \mathrm{m}$ in from the original position of the front surface, the next $0.6 \mu \mathrm{m}$ is melted, so only the back $0.8 \mu \mathrm{m}$ is solid and compressed. See Fig. 1. This solid portion, though, is not moving much; the place where the imprinted perturbations are growing is back at the ablation front, where the perturbations are clearly growing fluidlike. By $0.5 \mathrm{~ns}$ the entire foil is melted (Fig. 1) and decompressing from both ends. Thus, the actual foil distortion looks little different with and without strength (Fig. 2).

The 2-D calculations were done by imposing the measured speckle pattern on the beam incident on a 125-um-wide surface. Discrete Fourier transforms were done on both the line integrals (through the foil) of por and of optical depth 
$(\kappa \rho d r)$ vs spatial position across the foil, where $\kappa$ was obtained using the opacity tables you sent me." Then, I did a five-point smoothing of the Fourier powers vs mode number. The results are shown in Fig.'s 3 \& 4 for the low-intensity no-strength case; in Fig.'s 5 \& 6 for the low-intensity case with strength; and in Fig.'s 7 \& 8 for the high-intensity case. It can be seen that the amplitudes and general shape of the power spectra are consistent with the data, but differ in some details. Note that I am plotting just mode numbers up to 50, which corresponds in my calculation to a wavelength of 5 microns. Your data at higher mode numbers probably should not be believed, because they correspond to wavelengths below the spatial resolution of your imager.

We see in Fig.'s 3-6 (the low-intensity case without and with strength) that modes 2-10 ( $\lambda=25-125 \mu \mathrm{m})$ and modes 20-30 ( $\lambda=8-$ $12.5 \mu \mathrm{m}$ ) grow with time (power in $\rho r$ ); however, the power in optical depth in the low mode numbers decreases with time while in the higher mode numbers it grows with time, so the power spectrum (in optical depth) becomes more peaked with time at mode 20-30 (compared to mode 15-20, $\lambda=11-15 \mu \mathrm{m}$, in the data). The peak power in optical depth at 0.6 ns is about the same in the simulation as in the data, 0.003. The reason why the peak power is higher at the same time in the high-intensity case (Fig. 8) is simply because of the ten times higher intensity driving the perturbation growth. Another way of saying this is that the lower growth in the low-intensity case is because of the lower drive intensity, NOT because of material strength stabilization.

The power spectra in pr is little different between the strength and no-strength calculations (Eig.'s 3 \& 5). The peak power at mode 27 in the no-strength calculation is about 150 greater than that in the strength calculation. This result does not change much by greatly increasing the material strength; I did the same 2-D calculation with strength with the assumption that the aluminum had the strength of Vascomax steel, which has an ambient yield strength 40 times that of $1100 \mathrm{Al}$. (For the low-intensity calculation with strength I used the Steinberg-Guinan elastic-plastic constitutive model with the strength parameters for Al 1100, the weakest of the various flavors of Al; remember that the foils were vapor deposited from relatively pure metal, so the actual strength was probably even less than for 1100.) There is somewhat more difference 
in the strength and no-strength power spectra in optical depth (Fig.'s 4 \& 6), particularly at the low mode numbers, which suggests that the decrease in power in optical depth with time here is entirely an opacity effect (opacity decreases with decompression). The perturbations are certainly growing even while the optical depth is decreasing. Eurther, the fact that the simulated change with time in optical depth powers at a given mode number (or averaged over the mode numbers between 1 and 50) does not exactly match the data, means, I believe, that the opacity model is not quite right. Fig. 9 shows the calculated opacity fractional change vs time of the foil for the low-intensity and high-intensity cases; these results look to be within the error bars of your measurements, which gives us some confidence that the basic hydro is right and that the opacity is not grossly wrong. The opacity stays up at late times in the pulse because the material, although decompressing, is getting a lot hotter. I am sure, however, that we do not have the opacity modeling quite right.

Since it turns out that this is not a good experiment for showing material strength effects (we would need a much thicker foil for such an experiment, but then the xuv laser could not see through it), my colleagues and I here have no interest in doing a paper on this. I, however, would be happy to help you write up some comparison of your data to simulations (much like what I have written in this letter) to incorporate in any paper you decide to write on the Vulcan imprint experiments, in exchange only for you listing my name as a co-author. I think you should also include $\mathrm{S}$. V. Weber as a co-author, too, because he provided a lot of help to me in getting these calculations done.

* I had to make a couple of assumptions on how to extrapolate your opacity tables to low densities. For the solid tables I assumed that all the curves extrapolate linearly to zero opacity at zero density. For the liquid tables, since all the curves are flat (constant opacity) between 1.5 and about $2.5 \mathrm{gm} \mathrm{cm}^{-3}$ I assumed they remain flat below $1.5 \mathrm{gm} \mathrm{cm}^{-3}$, except that the opacity is, of course, zero at zero density. The final assumption is that the material is transparent above $20 \mathrm{eV}$. With these assumptions I then found the opacity for each grid cell in the calculation by linear interpolation 
in both temperature and density. The foil opacity at a given time (Fig. 9) is then the average of all the $\int \kappa \rho d r / \int \rho d r$.

Sincerely,

Jeff Colvin

Lawrence Livermore National Laboratory

Copies:

Dan Kalantar, LLNL

Bruce Remington, LLNL

Justin Wark, Oxford

Steve Weber, LLNL 


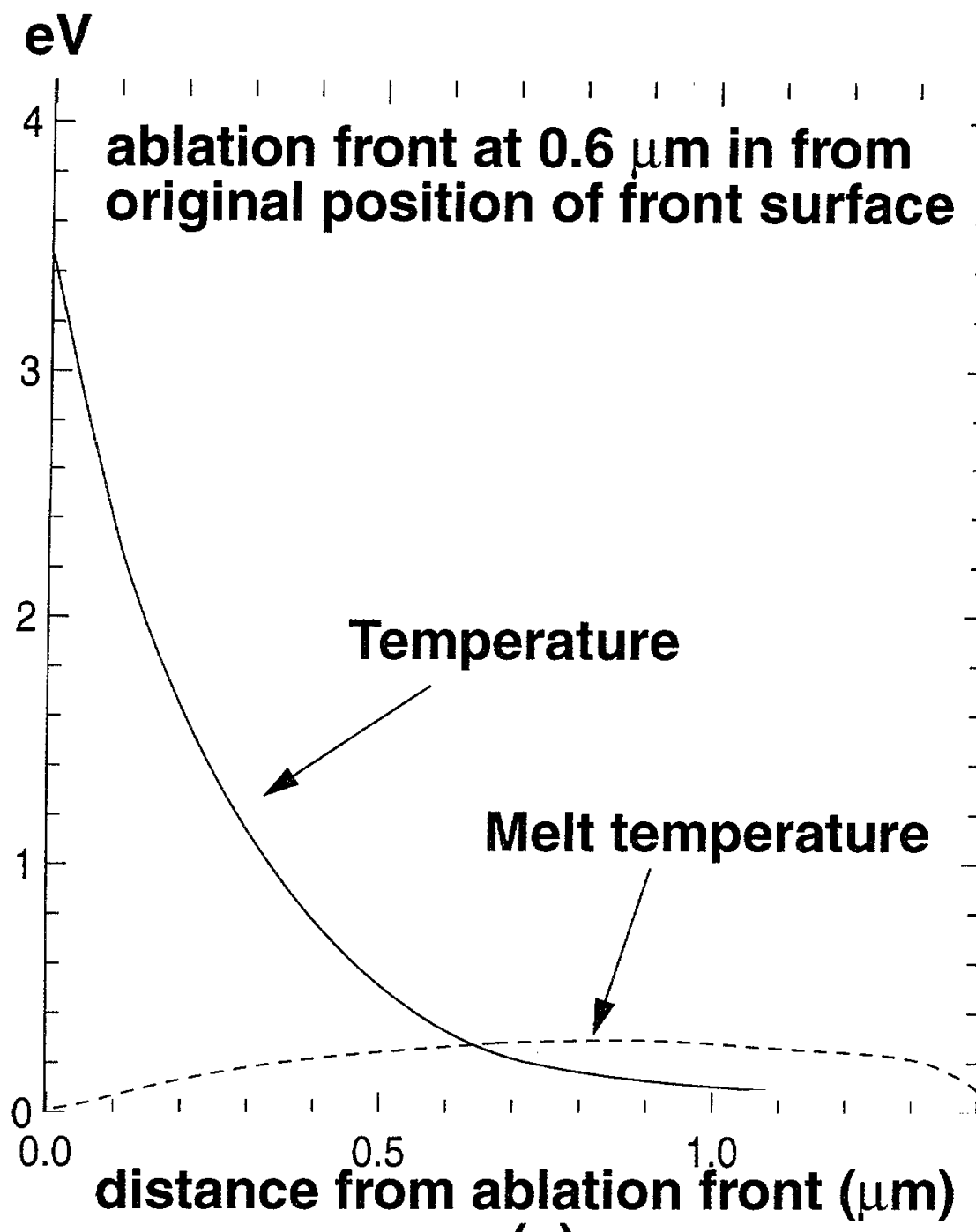

(a)

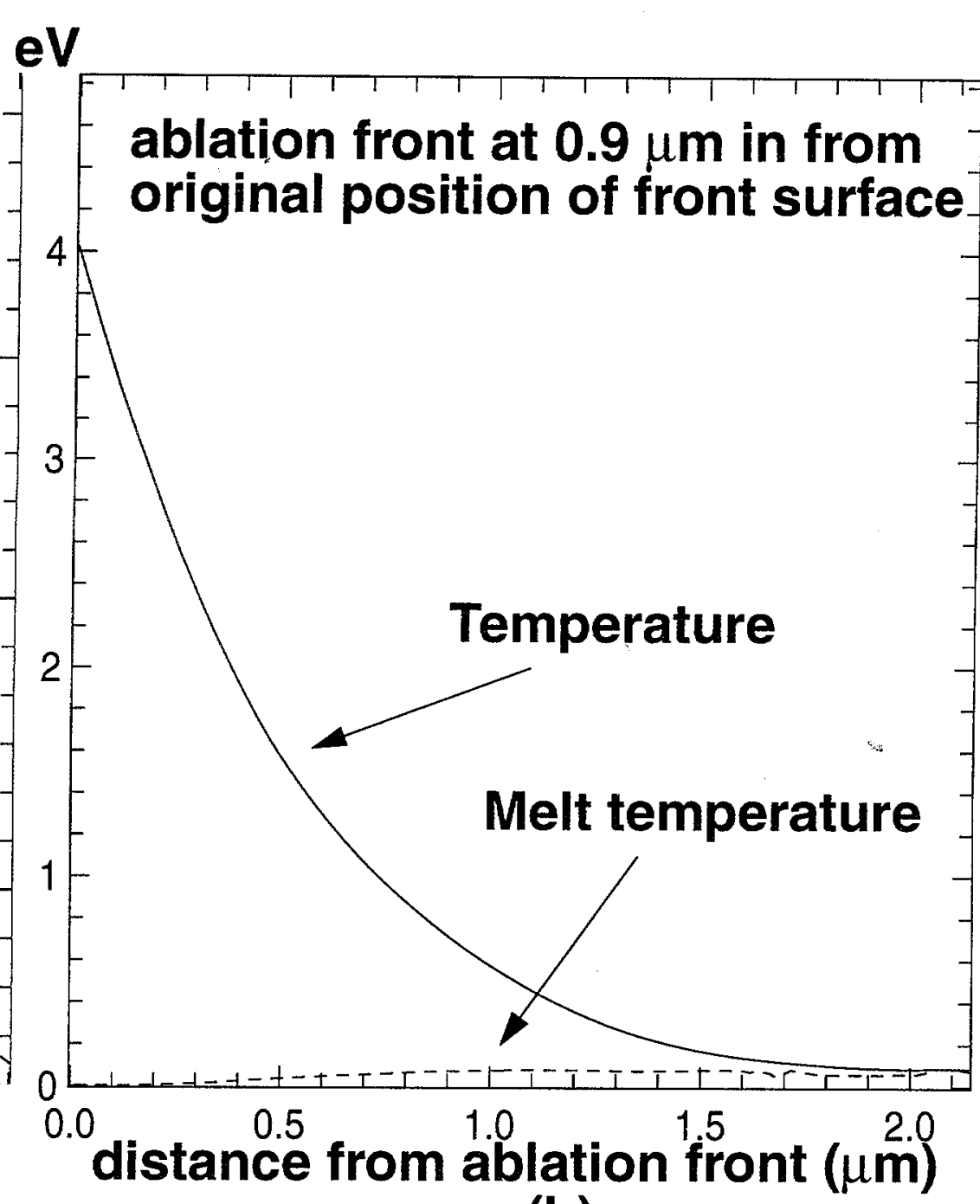

(b)

Figure 1. Temperature profiles at a) $0.3 \mathrm{~ns}$ and b) $0.5 \mathrm{~ns}$. 
mesh at $0.3 \mathrm{~ns}$

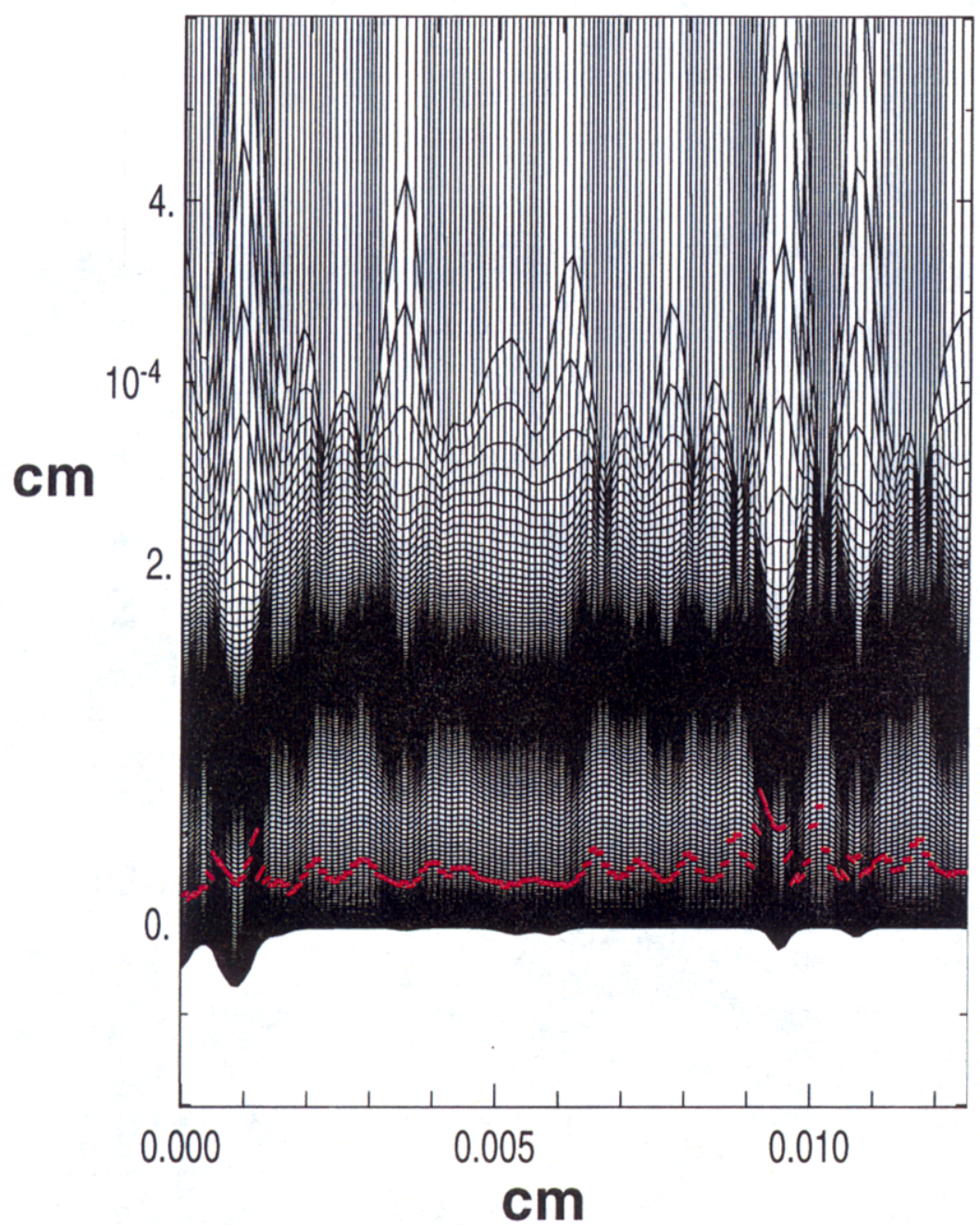

(a)

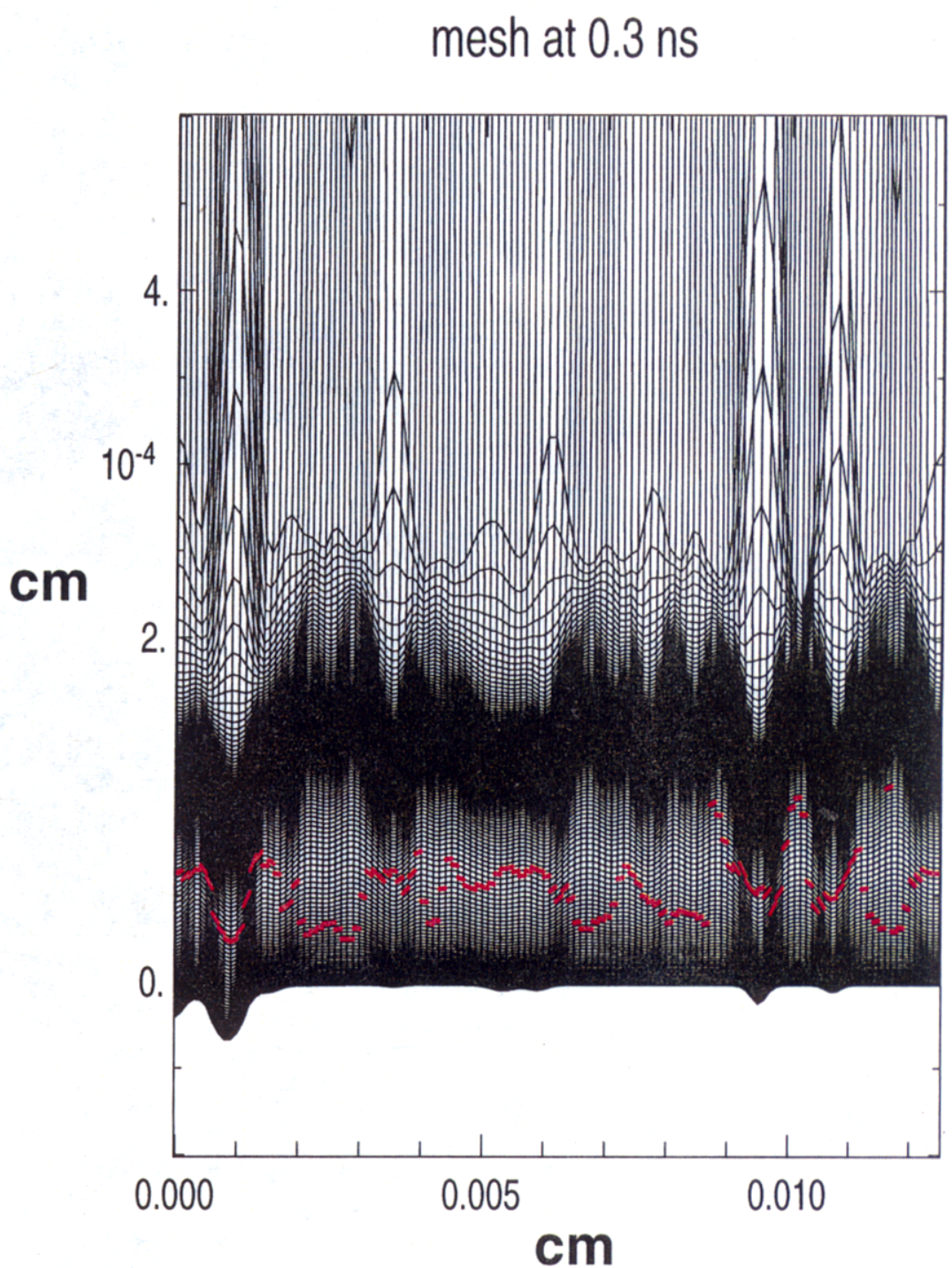

(b)

Figure 2. 2-D mesh at 0.3 ns showing the position and shape of the ablation front (red curve) for calculation a) with Steinberg-Guinan material strength and b) with no strength. 
Fourier power (rho-r), smoothed, vs mode no.

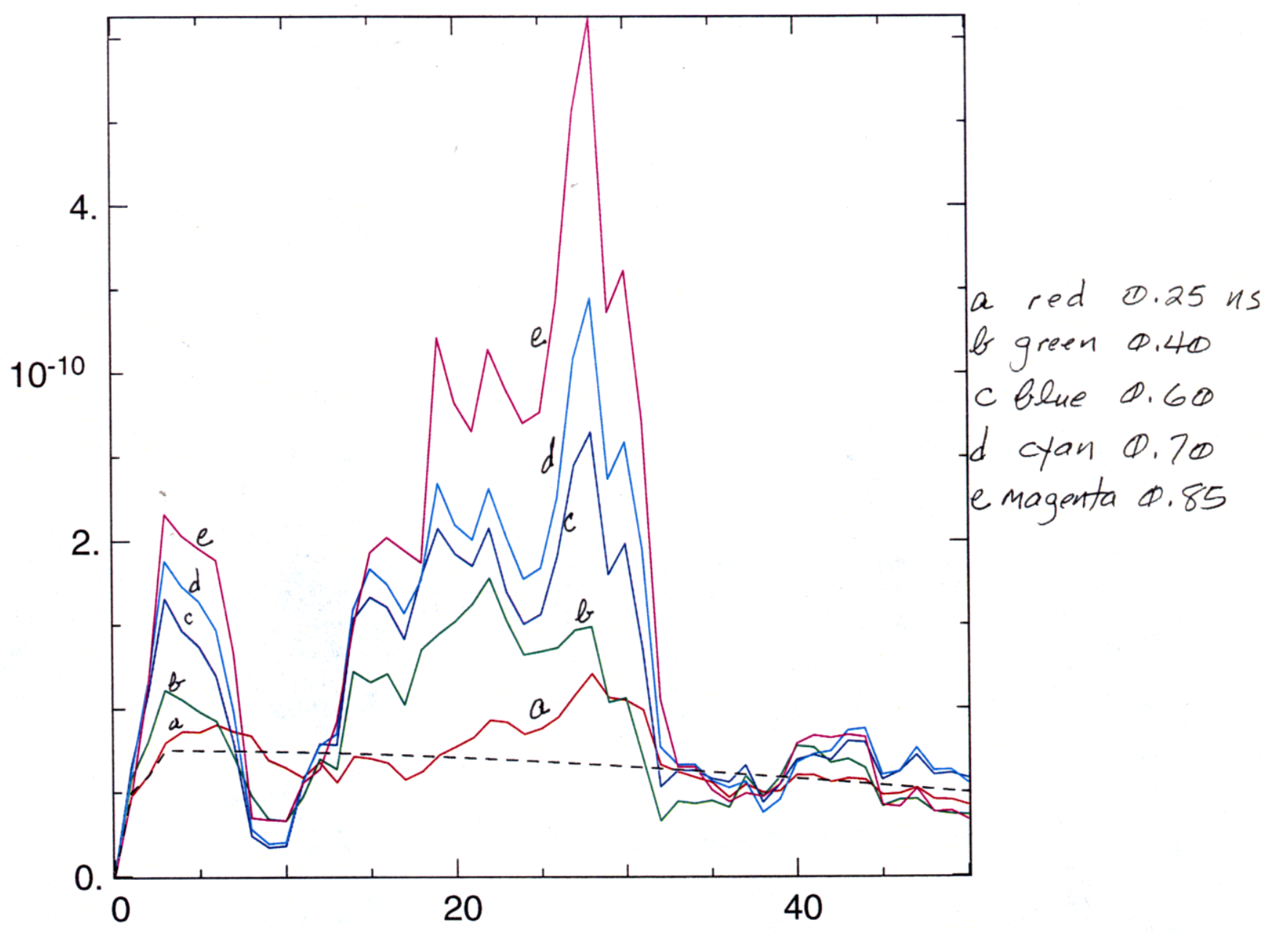

low intensity, no strength

Fig. $3 a$ 


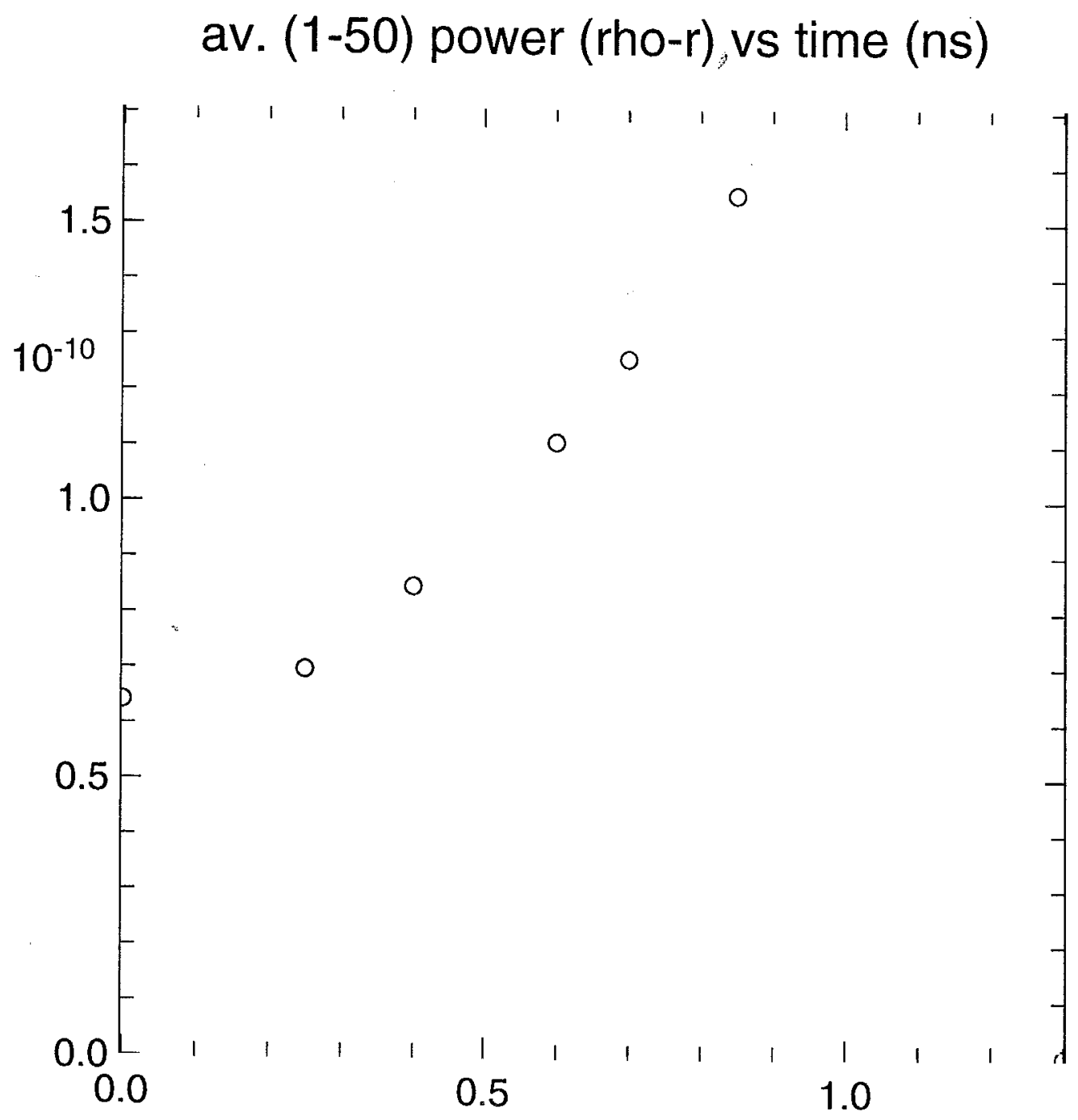

low intensity, no strength

Fig. $3 b$ 
Fourier power (optical depth), smoothed, vs mode no.

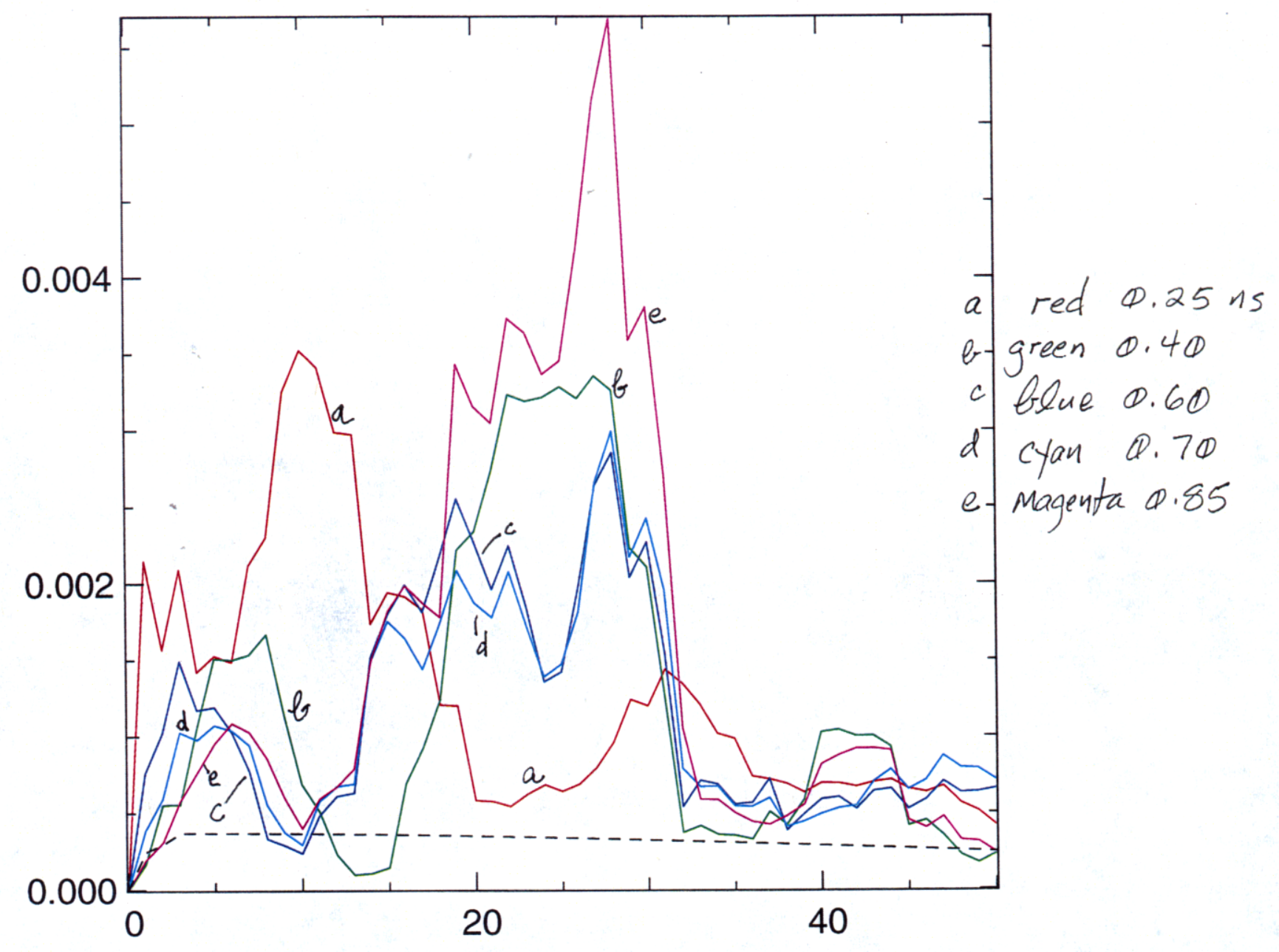

low intensity, no strength

Fig. $4 a$ 
av. (1-50) power (optical depth) vs time (ns)

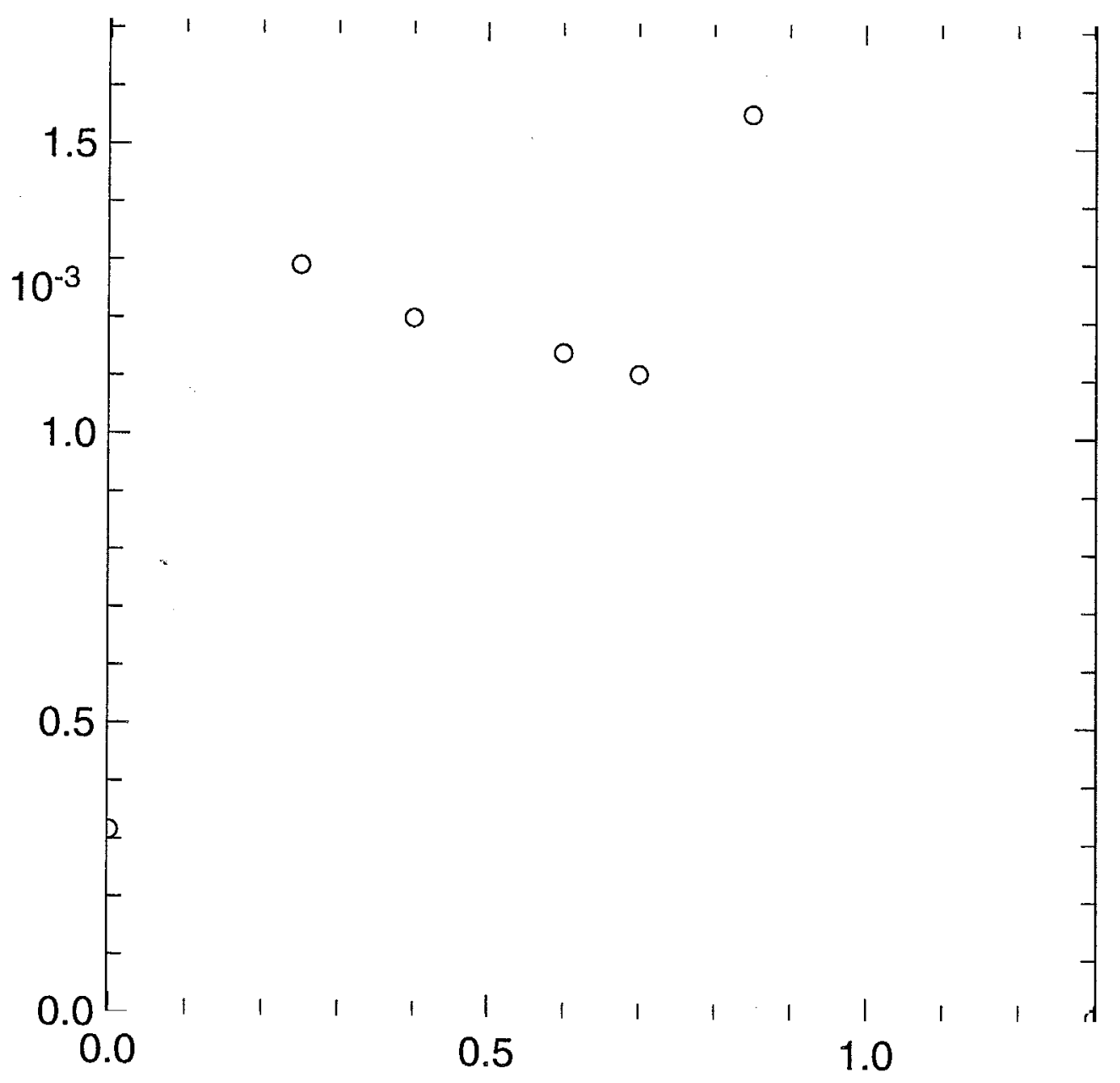

low intensity, no strength

Fig. $4 b$ 
Fourier power (rho-r), smoothed, vs mode no.

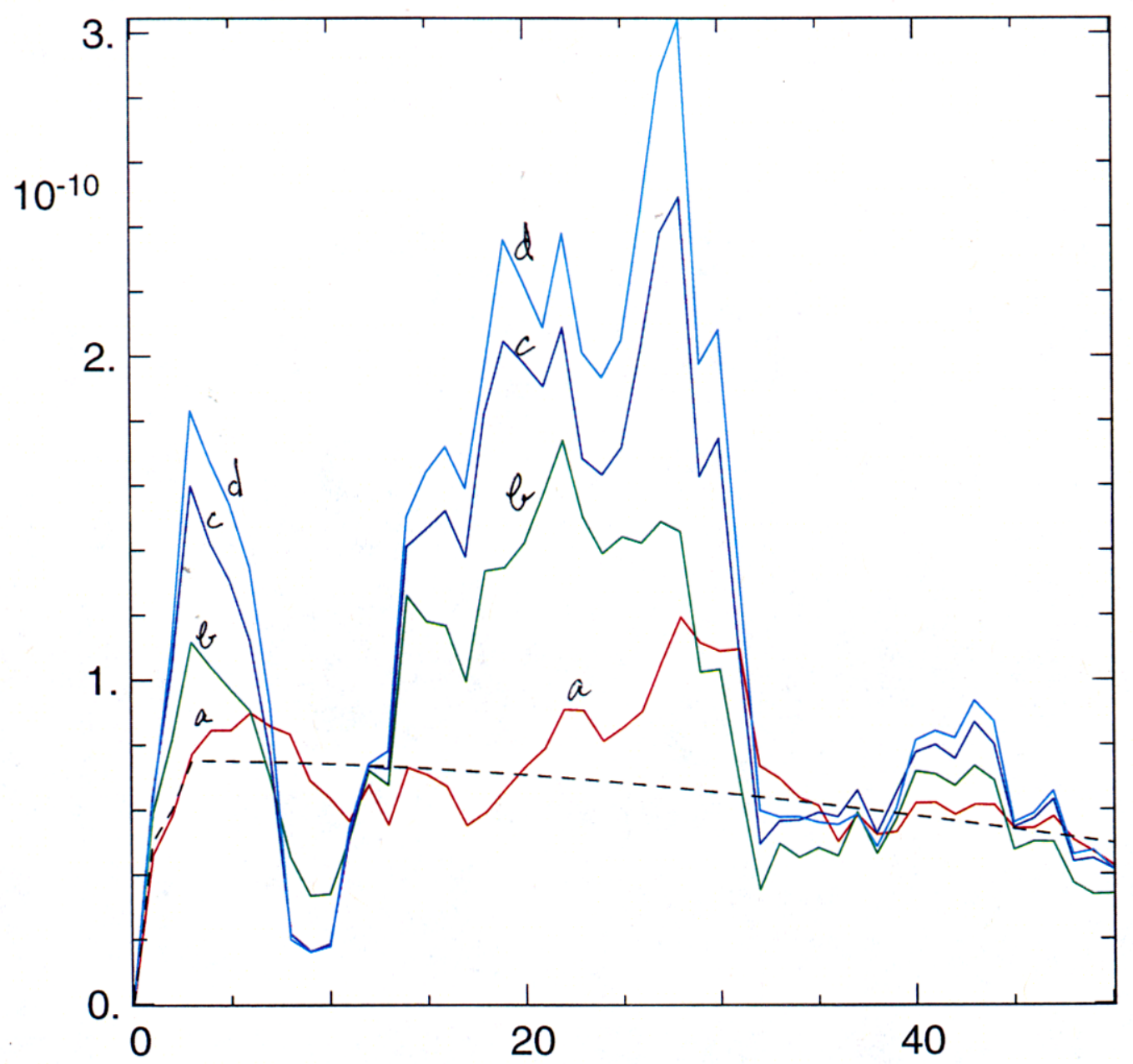

low intensity, with strength

Fig. $5 a$ 


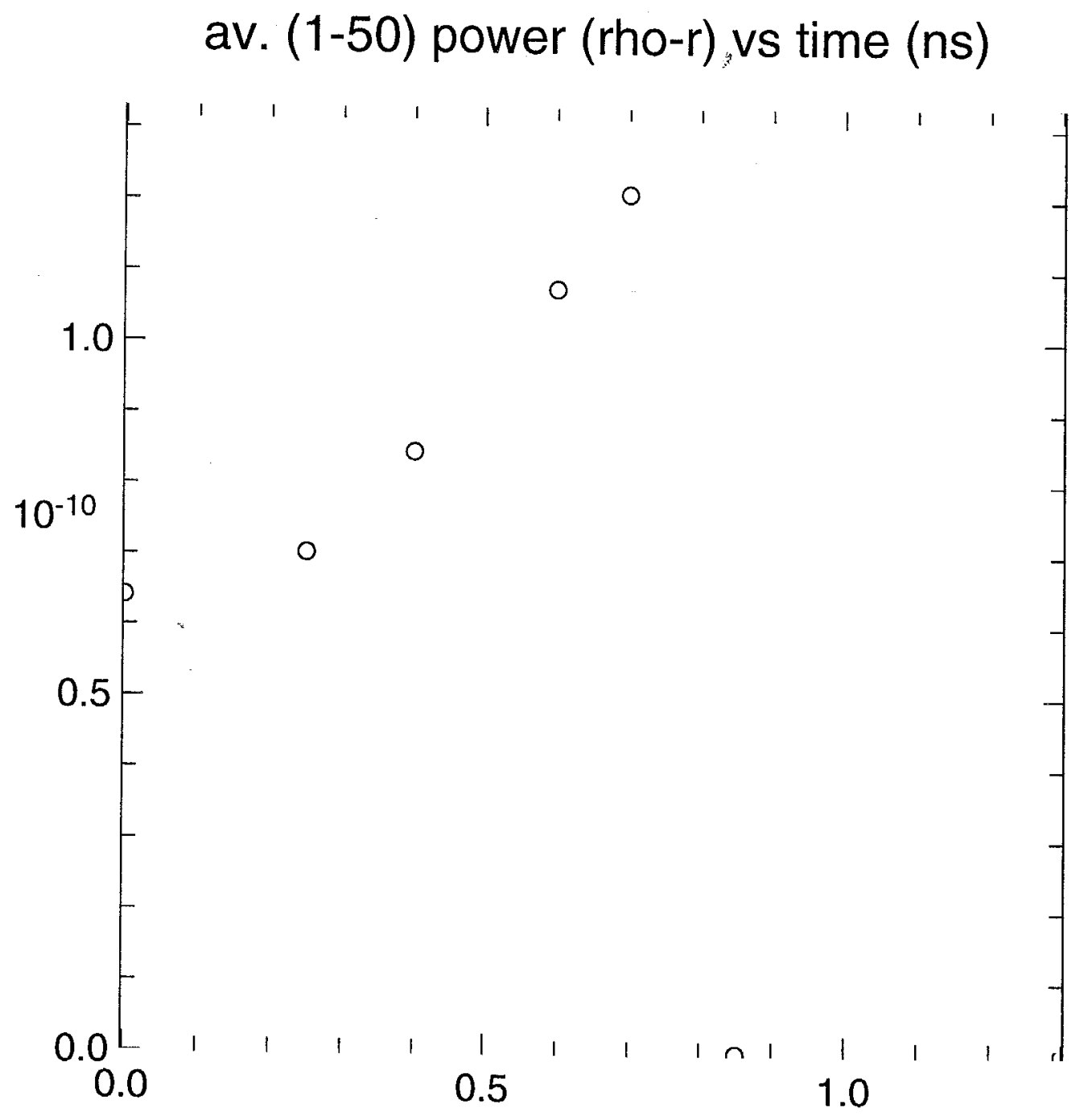

low intensity, with strength

$$
\text { Fig. } 5 b
$$


Fourier power (optical depth), smoothed, vs mode no.

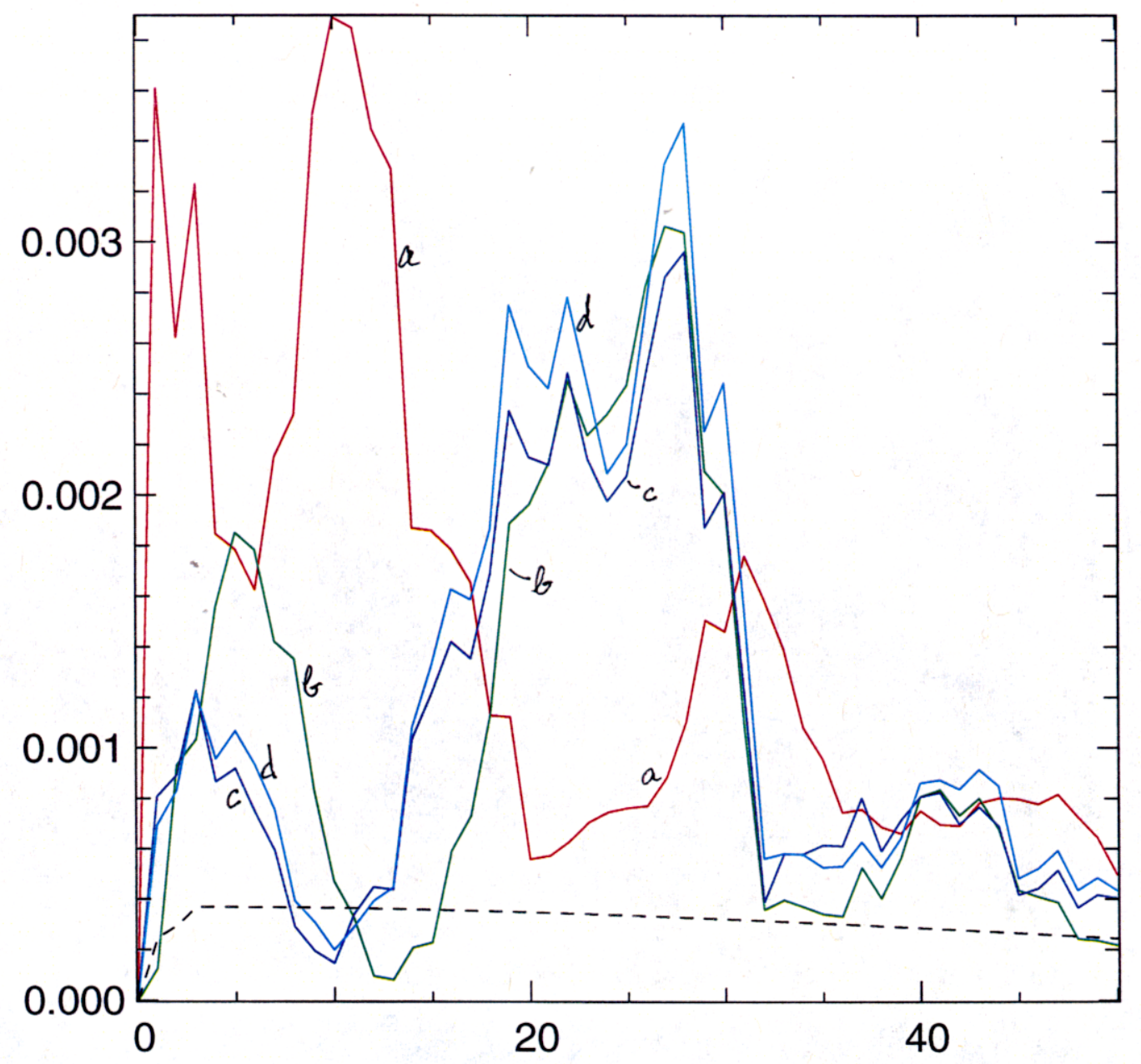

low intensity, with strength

Fig. $6 a$ 


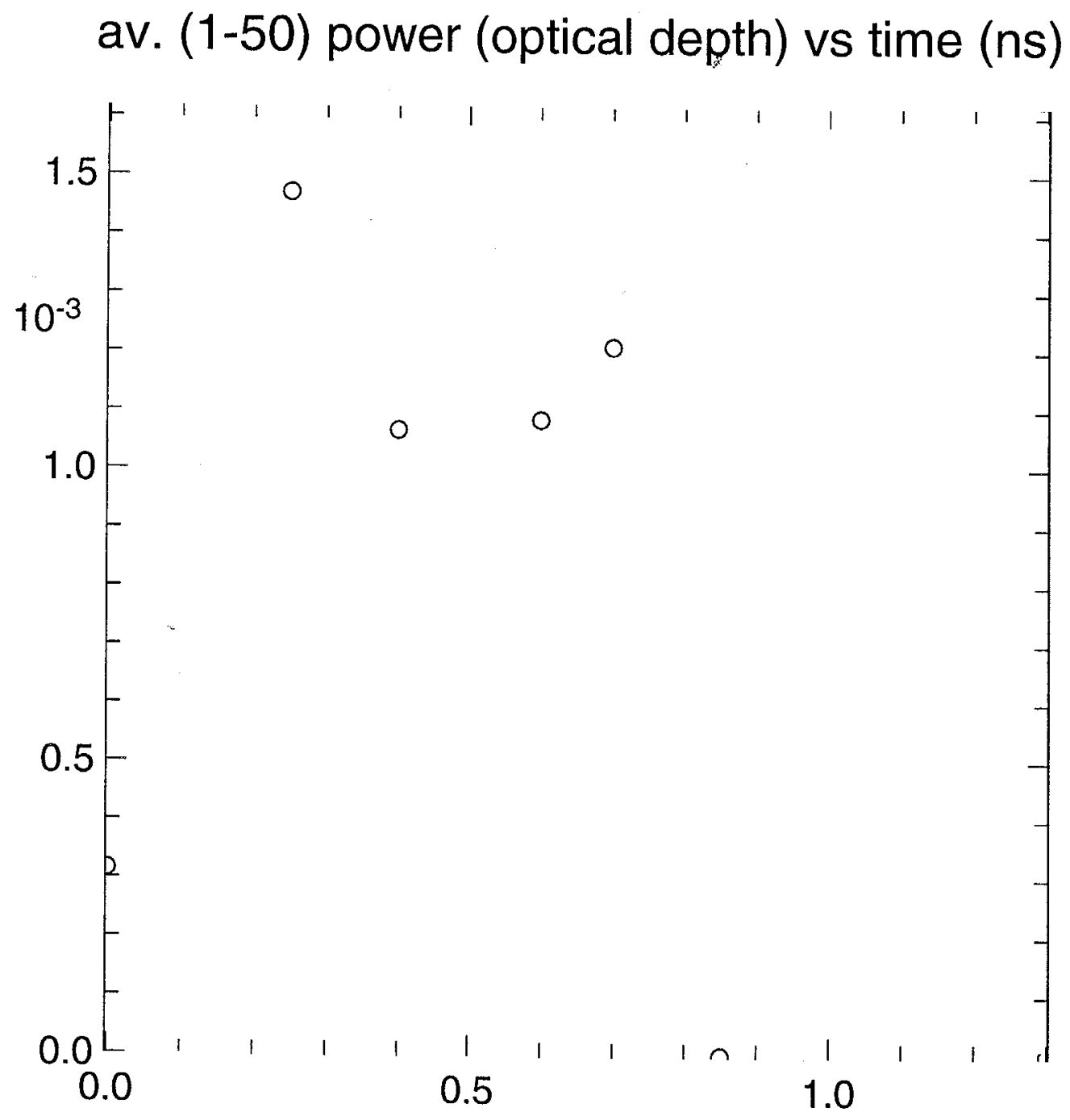

low intensity, with strength

$$
\text { Fig. } 6 b
$$


Fourier power (rho-r), smoothed, vs mode no.

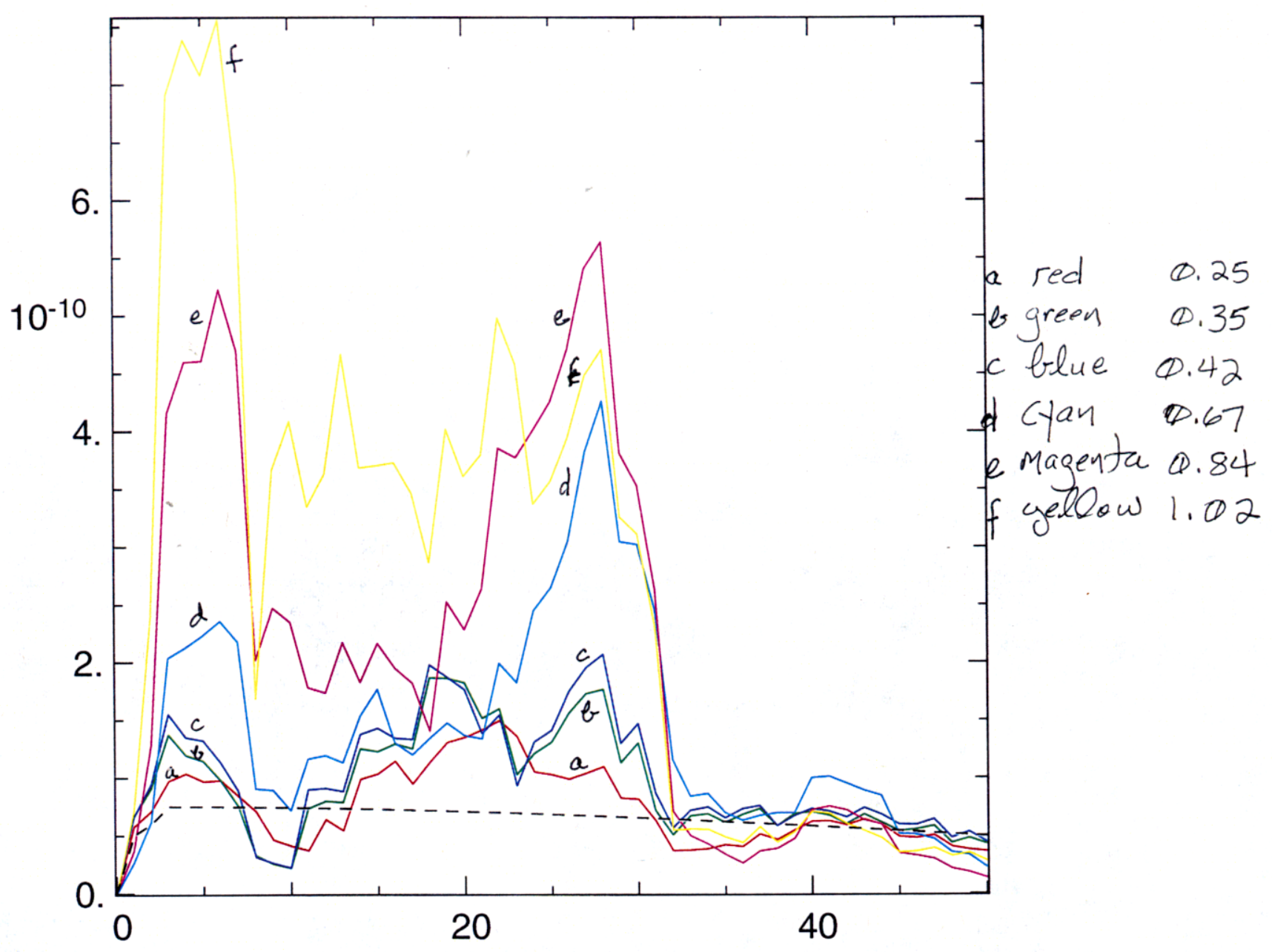

high intensity

Fig. $7 a$ 


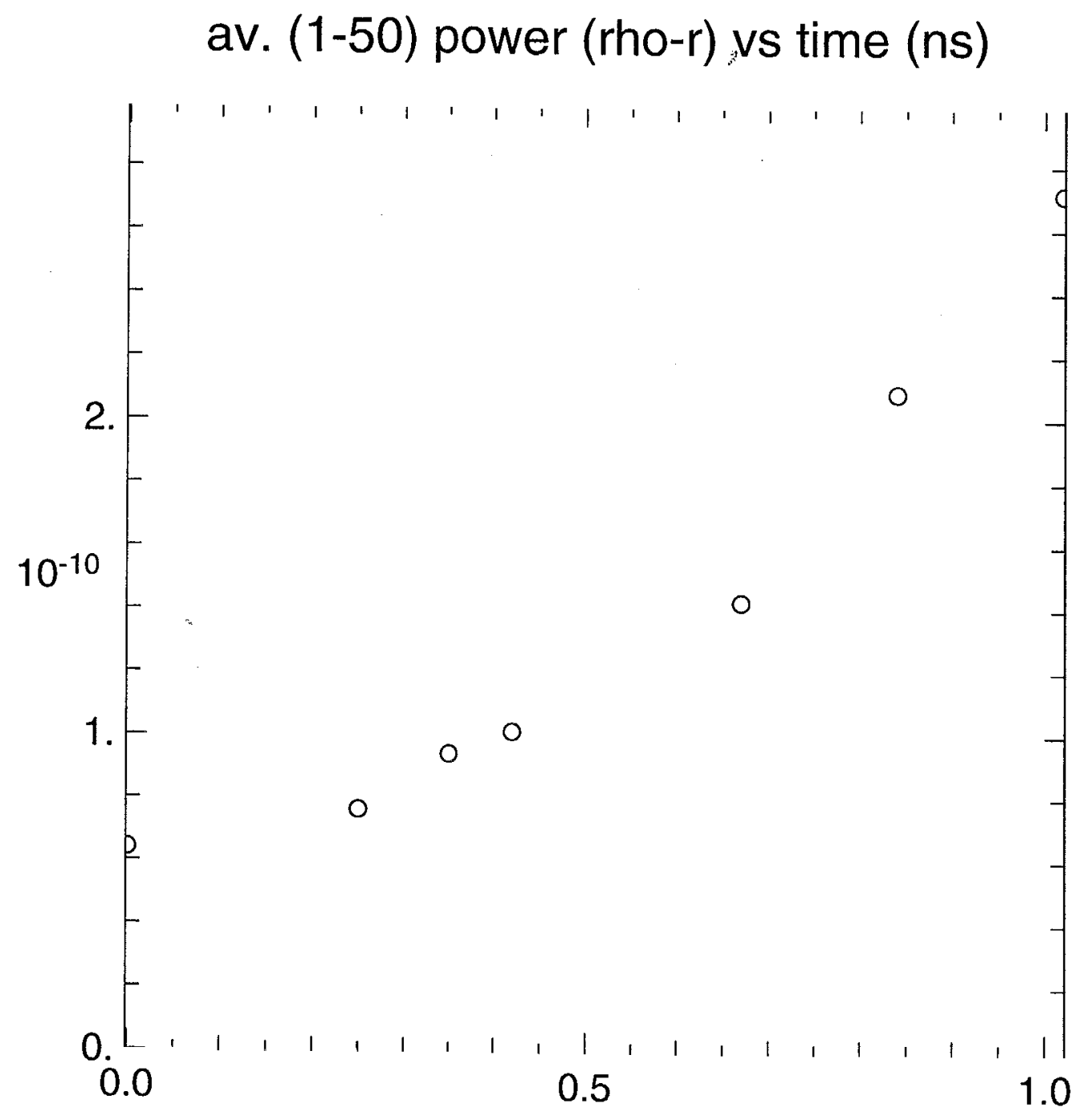

high intensity

$$
\text { Fig. } 7 b
$$


Fourier power (optical depth), smoothed, vs mode no.

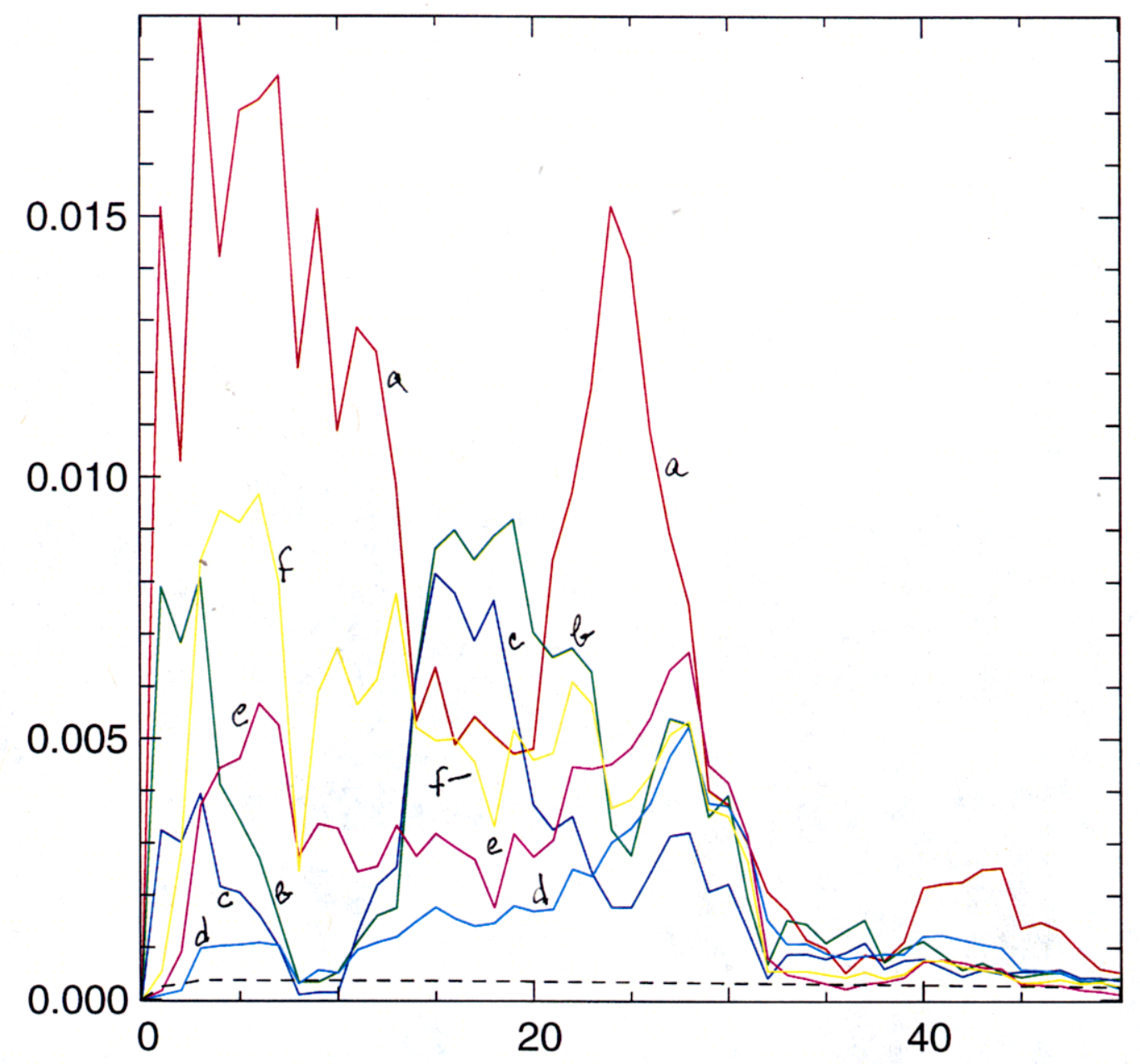

high intensity

$$
\text { Fig. } 8 \text { a }
$$




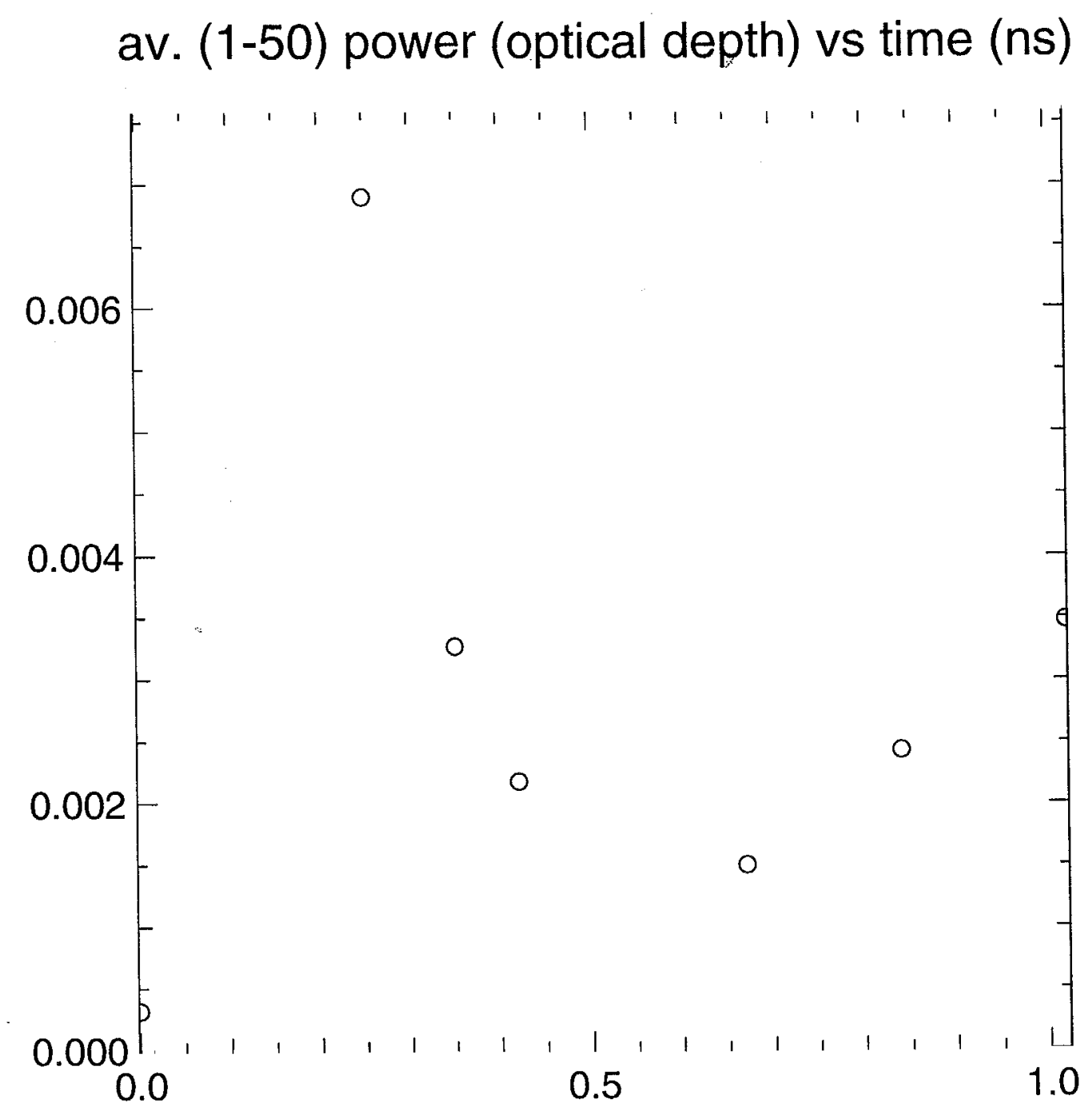

high intensity

Fig. $8 b$ 


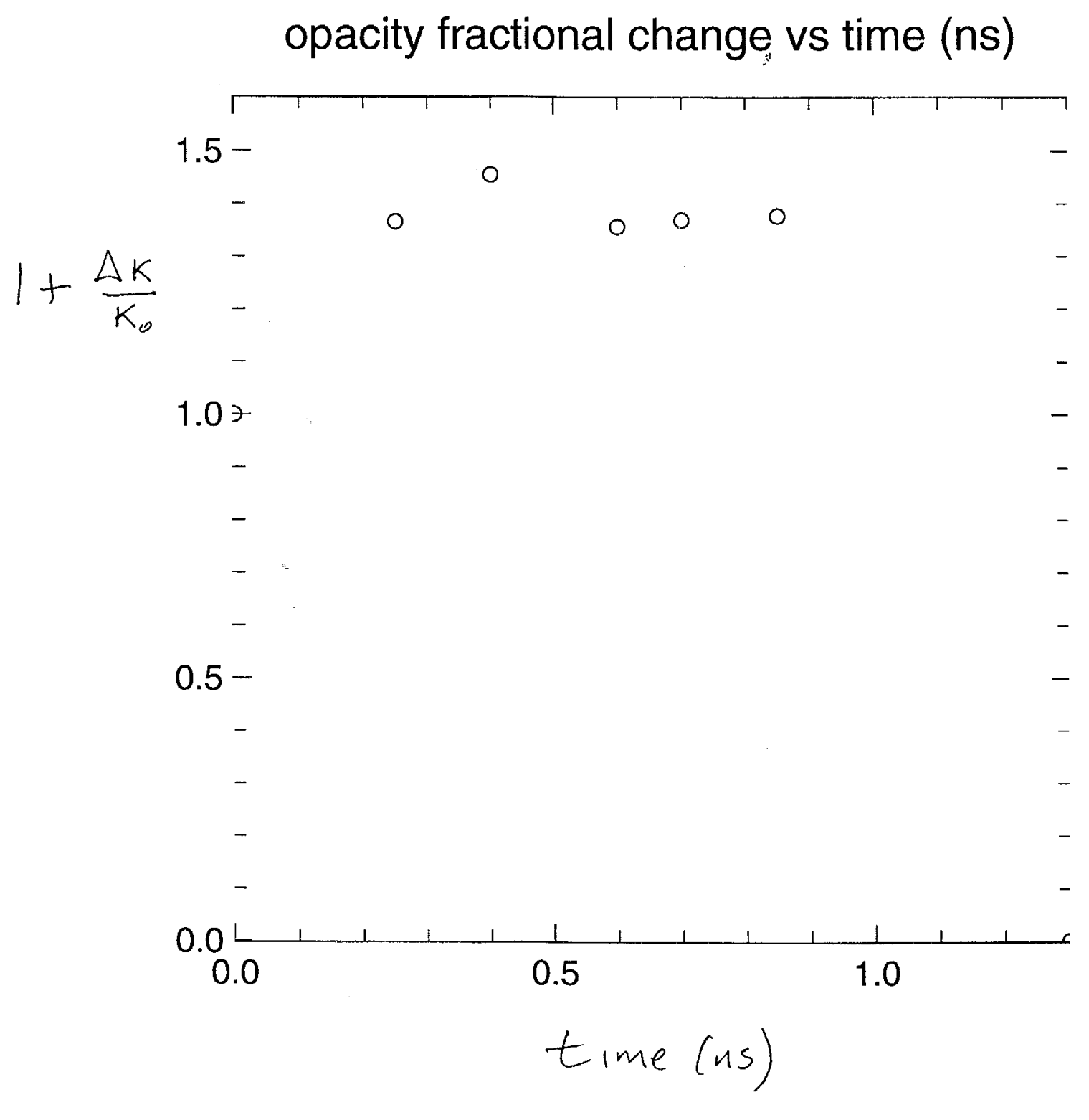

Low intensity case $\left(0,5 \times 10^{12} \mathrm{~W} / \mathrm{cm}^{2}\right)$, no strength

Fig. 9 a 
opacity fractional change vs time (ns)

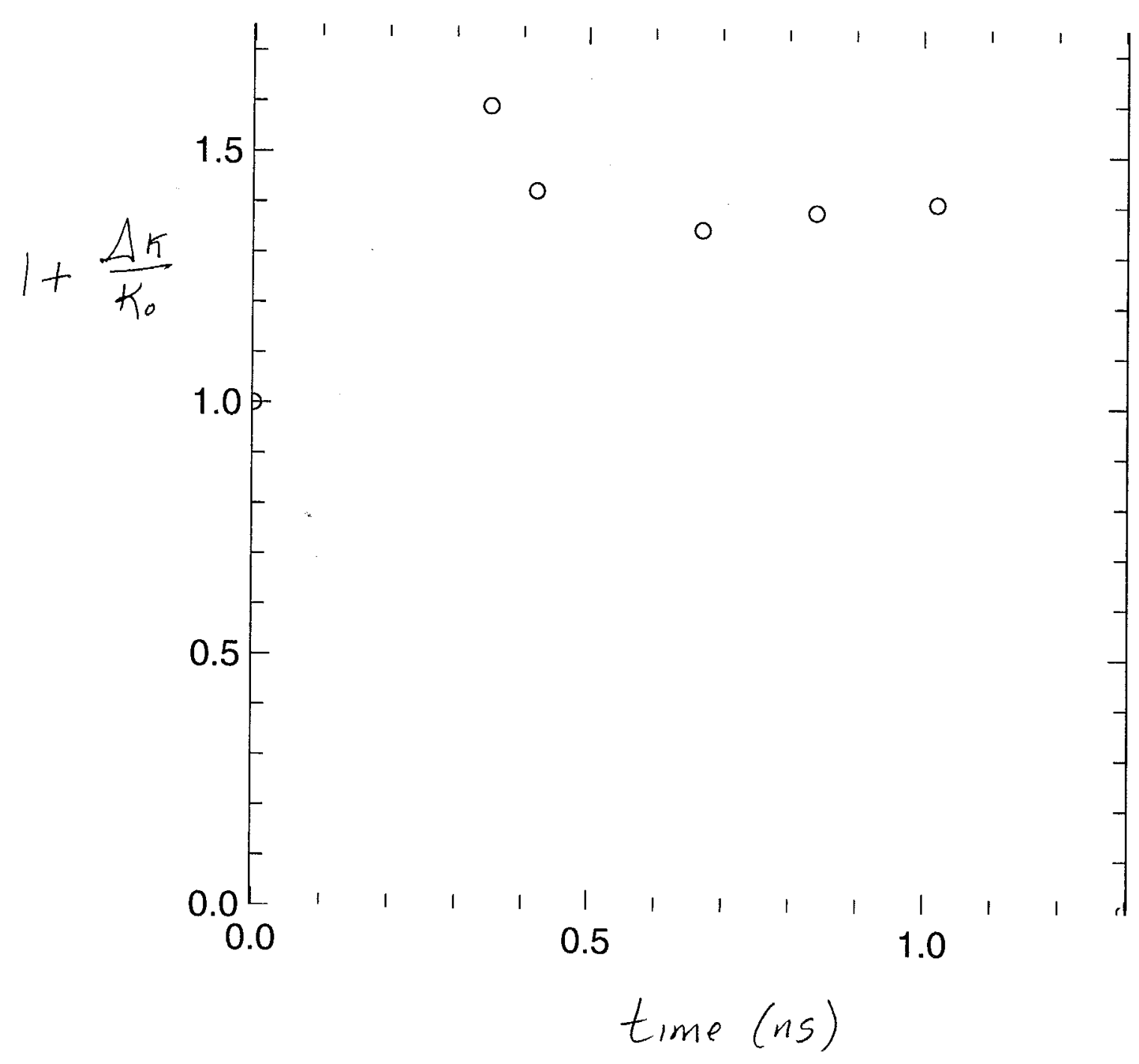

High-intensity case $\left(5 \times 10^{12} \mathrm{~W} / \mathrm{cm}^{2}\right)$

$\mathrm{Fg} \cdot 9 \mathrm{~b}$ 